Gazi University
Journal of Science
$\mathrm{http}: / /$ dergipark.gov.tr/gujs

\title{
Modelling and Simulation of 1 MW Grid-Connected PV System Regulated by Sliding Mode Control, Model Predictive Control and PI Control
}

\author{
Ercan MACIT* ${ }^{*}$, Ahmet Mete VURAL (i) \\ Gaziantep University, Engineering Faculty, Electrical and Electronics Engineering Department, 27470, Gaziantep, Turkey
}

\begin{abstract}
Highlights
- Design and control of $1 \mathrm{MW}$ grid-connected PV system.

- Sliding mode control, model predictive control, and PI control methods for PV system control.

- Performance comparison of sliding mode control, model predictive control, and PI control.

Article Info

Received: 19 Mar 2021

Accepted: 05 Dec 2021

\section{Keywords}

Photovoltaic system Grid-connected mode Sliding mode control MPC control PI control

Abstract

The design and modeling of a 1 MW grid-connected multistage PV system consisting of four equal power rated PV arrays are presented. Two nonlinear control methods, namely sliding mode control and discrete time model predictive control with finite switching states are adopted as the current control scheme of the inverter together with the parameter update for the LCL filter for each control mode. The proposed controllers are based on coordinate transformation of the variables and use decoupling to improve control performance. The dynamic and steady-state performances of these controllers have been thoroughly evaluated and compared with the conventional decoupled PI current control scheme in Matlab Simulink environment under fixed and changing weather conditions. It is observed that the performances of the controller schemes are satisfactory and they give almost similar steady-state performances under given test conditions, although there are little changes observed during system starting.
\end{abstract}

\section{INTRODUCTION}

Access to energy is essential for good living conditions, poverty reduction, and economic development. In recent years, growing population with increasing energy demand has significantly updated the methods for global energy production from conventional fossil fuel-based power stations due to environmental concerns. Consequently, there are feverishly ongoing studies worldwide to use clean energy sources efficiently and uninterruptedly due to swelling anxieties for environmental damage. The world now inevitably requires an effective transition from conventional to alternative energy sources to sustain global climate targets and supply sustainable energy access to everyone. The foremost practices of renewable energy types are wind and solar to produce electricity in large amount due to their ample and non-stop characteristics. On the other hand, grid-connected renewable energy systems aim to continuously synchronize the renewables to the utility grid with the possible greatest amount of production, mostly without the need for expensive energy storage systems. Although, grid-connected photovoltaic (PV) system is not popular as wind at the utility-scale, it is a more practical option for residential energy production and it can be made available almost anywhere where there is abundant sunlight. The design and control of the grid-connected photovoltaic systems have critical importance for generating electricity efficiently from the solar energy and transferring it to the grid via synchronization. In this context, a $1 \mathrm{MW}$ rated grid-connected PV system is designed and modelled from scratch in this study. The proposed PV system is composed of four identical $250 \mathrm{~kW}$ rated PV arrays operating in parallel with the grid and loads. Figure 1 shows the simulation model of the PV array connected to the grid, such as PV array, DC-DC converter, inverter, LCL filter, and coupling transformer. It is well known that the operating point of a PV supply moves away from its optimal location whenever there is a change in solar irradiance and temperature. Thus, in this study, the control of the DC-DC converter is realized with a maximum power point tracking (MPPT) algorithm to 
excerpt the maximum power from the PV system. Although there are many MPPT algorithms adduced in the literature based on direct, indirect or soft computing methods, one of the well-known direct methods, such as incremental conductance with an integral regulator is preferred in this work to track the maximum power operating point of the PV system under altering environmental conditions. The inverter used in this renewable system is a three-phase three-level neutral point clamped (NPC) inverter to provide an interface between DC output of the DC-DC converter and the AC utility grid. On the other hand, recent studies exist regarding the application of different current control techniques for the inverter of grid-connected PV systems. For instance, sliding mode control (SMC) is applied in [1], model predictive control (MPC) is applied in [2], and simple PI control scheme is adopted for the current control scheme of the grid-connected inverter in PV applications [3]. In the literature, generally only one type of controller is preferred for the inverter control in grid-connected PV systems. In this work, two nonlinear control techniques such as SMC and discrete time MPC with finite set model are adopted as the current controller for the NPC inverter. In this study, the advantages and disadvantages of the aforementioned control techniques applied to $1 \mathrm{MW}$ grid-connected multistage PV system are evaluated. The most important positive feature of the PI control technique is observed in that it significantly reduces the steady-state error. Moreover, the response of PI control scheme is faster than the other control methods due to the proportional gain. The other advantage of PI control scheme is its simplicity to design and practically applicable. On the other hand, the most important negative feature of the PI-based control is its inadequate response to sudden changes in the system and its hypersensitivity to controller gains [4]. MPC technique is accepted as an effective control approach for grid connected inverters, especially for real-time control tasks. MPC has many advantages such as fast dynamic response, less sensitivity to disturbances, capability for tracking reference current and voltage values to meet the needs of the utility grid and good capability of handling the nonlinearities of the power plants [5]. However, there are some disadvantages of the MPC technique and the most important classical one is the required processing time especially when the high switching frequencies are applied in power electronic applications. However, this case requires huge calculation effort for real-time implementation of the MPC applications which is met with the latest fast processors. Another apparent disadvantage of MPC is its complex algorithm when compared to other simple control methods such as PI control. MPC algorithm involves the dynamic models of the controlled system. More iterative computational works in each step time have to be completed because the MPC algorithm contains too many control parameters. On the other hand, SMC has a nonlinear control mechanism which is more used than other nonlinear control methods because of its high robustness and ability to tolerate to changing system parameters and external disturbances. The main purpose of the SMC control technique is to restrict the system to the ranges where the system can respond appropriately, so that the system remains on the slip surface where it will show the desired properties with the appropriate control strategy. Although, the SMC may give sufficient response in transient mode in some control systems, it may not give sufficient response in steady-state, since this control technique contains discontinuous control which provokes chattering problem. For SMC, the system model has to be also needed as well. Like MPC, SMC has also more computational tasks that have to be done because SMC contains too many control parameters. In this study, the dynamic as well as steady-state performances of MPC and SMC control methods are compared with the conventional PI current control scheme. Hence, the highlight of this research is to provide a recent comparison between the aforementioned inverter current control techniques both in steady and dynamic states under various operating conditions for a grid-connected multistage PV system. There are many studies in the literature that analyze and compare the performances of these control systems applied to different dynamic systems [6-9]. The paper is organized into six sections. Section 2 deals with the design of each component in the system that connects $250 \mathrm{~kW} \mathrm{PV}$ array to the grid. The DC-DC converter control and NPC inverter control schemes are mentioned in Sections 3 and 4, respectively. The simulation results and the discussion are presented in Section 5, while Section 6 summarizes the work. The simulation model of the PV array connected to grid with PV array, DC-DC converter, inverter, LCL filter, and coupling transformer is illustrated in Figure 1.

\section{MATERIAL METHOD}

The designing and controlling steps of $1 \mathrm{MW}$ rated grid-connected PV system are explained in this paper. The proposed PV system is composed of four identical $250 \mathrm{~kW}$ rated PV arrays operating in parallel with the grid and loads. This PV system consists of PV array, DC-DC converter, inverter, LCL filter, and coupling transformer. 


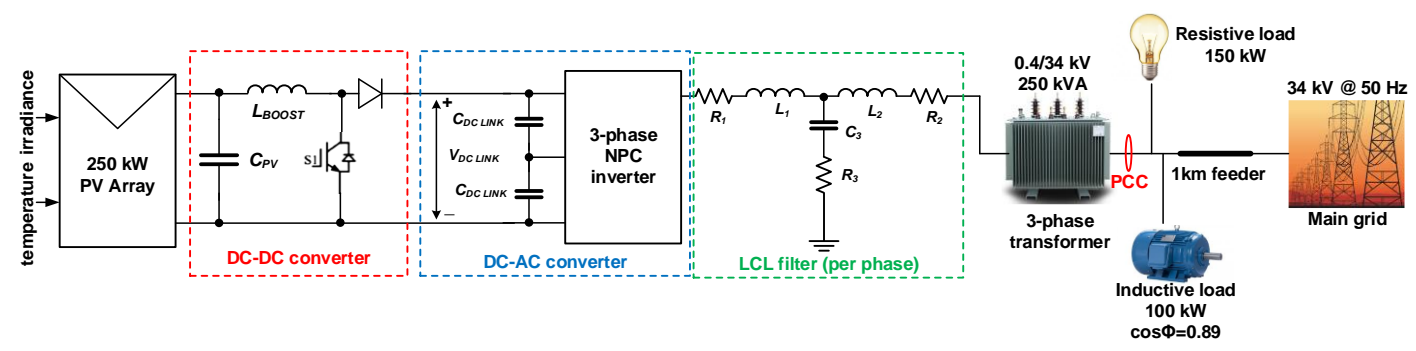

Figure 1. Multistage model of $250 \mathrm{~kW} P$ V array connected to grid

In this study, the control of the DC-DC converter is implemented with a maximum power point tracking (MPPT) algorithm to acquire the maximum power from the proposed PV system. The incremental conductance with integral regulator is preferred in this work to track the maximum power operating point of the PV system under changing environmental conditions. SMC, MPC and PI control techniques are applied for controlling the designed PV system. The dynamic and steady-state performances of these controllers have been thoroughly evaluated and compared with conventional decoupled PI current control scheme in Matlab Simulink under fixed and changing environmental conditions.

\subsection{PV System Design}

The choice of PV module is crucial in terms of installation costs and efficiency of the overall renewable energy system. Although monocrystalline silicon cell has higher efficiency than polycrystalline silicon cell, Suntech Pluto 250-Wdm PV module based on polycrystalline silicon cells is preferred in the design due to its low cost and availability. The efficiency of this module is $15.4 \%$ and contains $60(6 \times 10)$ cells with a dimension of $156 \times 156 \mathrm{~mm}$ for each [10]. The DC link reference voltage of the PV system has to be calculated for determining the number of series-connected PV modules. The minimum DC link voltage is determined such that,

$V_{D C_{-} L I N K} \geq 2 \sqrt{2} V_{P H A S E, R M S}=2 \sqrt{2} 230 \cong 653 V$

So, practically, the DC link voltage can be taken as $700 \mathrm{~V}$ as the output reference voltage of the DC-DC converter. Since, $30.8 \mathrm{~V}$ is the output voltage of each PV module, this voltage is represented with $\mathrm{V}_{\mathrm{MP}}$ in Equation (2), specified by the manufacturer. Next, the number of series connected PV modules $\mathrm{N}_{\text {SER }}$ is determined as,

$N_{S E R}=\frac{1}{2} \frac{V_{D C_{-} L I N K}}{V_{M P}} \cong 12$ Modules.

Then the rated power of each string composed of 12 modules is calculated as,

$P_{\text {STRING }}=12 \times 250 \mathrm{~W}=3 \mathrm{~kW}$.

where $250 \mathrm{~kW}$ is the rated power of each PV module. Next, the number of parallel-connected strings $\mathrm{N}_{\mathrm{PAR}}$ in each PV array is determined as,

$N_{\text {PAR }}=\frac{P_{\text {Plant }}}{P_{\text {STRING }}} \cong 84$ Parallels

where the rated power Plant is equal to $250 \mathrm{~kW}$ for each PV array. Finally, each PV array is designed with 84 parallel connected PV strings. Each string is composed of 12 PV modules connected in series. So, the required area for each PV array is calculated as [11], 


$$
A_{\text {Array }}=\frac{1008 \text { Modules } \times 1.626 m^{2}}{0.7} \cong 2.5 \text { Hectare } .
$$

Finally, $1 \mathrm{MW}$ power capacity is achieved using four PV arrays as shown in Figure 2. The PV arrays are designed as central structure type so that one DC-DC converter and one inverter are used to link each PV array to the grid. The components and other details of the overall PV system are given in Table 1.

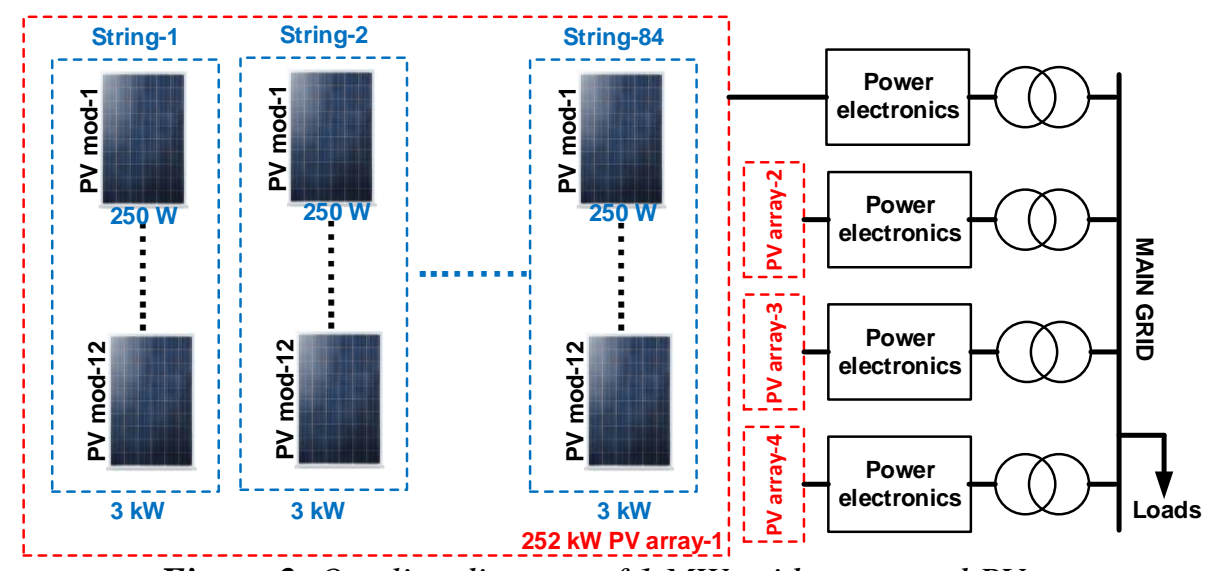

Figure 2. One line diagram of $1 \mathrm{MW}$ grid-connected PV system

Table 1. The components and details of the overall PV system

\begin{tabular}{|l|l|}
\hline Optimum operating voltage/current of PV module & $30.8 \mathrm{~V} / 8.34 \mathrm{~A}$ \\
\hline Number of series connected PV modules in each string & 12 \\
\hline Number of parallel connected strings in each PV array & 84 \\
\hline Number of PV arrays in the overall PV system & 4 \\
\hline Rated power/voltage/current of PV array & $250 \mathrm{~kW} / 360 \mathrm{~V} / 700 \mathrm{~A}$ \\
\hline Number of PV modules in each PV array / whole PV system & $1008 / 4032$ \\
\hline Rated power/voltage/current of each string & $3 \mathrm{~kW} / 360 \mathrm{~V} / 8.34 \mathrm{~A}$ \\
\hline Number of inverters / rated power in whole PV system & $4 / 250 \mathrm{~kW}$ \\
\hline Number and power rating of transformers in whole PV system & $4 / 250 \mathrm{kVA}$ \\
\hline Transformer rated parameters & $0.26 \mathrm{kV} / 34 \mathrm{kV}$ \\
\hline Required installation area for each PV array / whole PV system & $2.5 / 10 \mathrm{Hectare}$ \\
\hline Rated power of overall PV system & $1 \mathrm{MW}$ \\
\hline
\end{tabular}

\subsection{DC-DC Converter Design}

The DC-DC converter is a boost converter with an estimated efficiency $\eta_{\mathrm{DC}-\mathrm{DC}}$ of $90 \%$. The maximum duty factor $\mathrm{D}_{\mathrm{MAX}}$ is then calculated as follows according to the minimum voltage of the converter $\mathrm{V}_{\mathrm{MIN}}=500 \mathrm{~V}$,

$D_{M A X}=1-\frac{V_{M I N} \eta_{D C-D C}}{V_{D C_{-} L I N K}}=0.64$.

The maximum value of the IGBT current $\mathrm{I}_{\text {IGBT_MAX }}$ is calculated as [12],

$I_{I G B T_{-} M A X}=2 I_{I N V_{-} R M S}\left(D_{M A X}+1\right)=1401 \mathrm{~A}$.

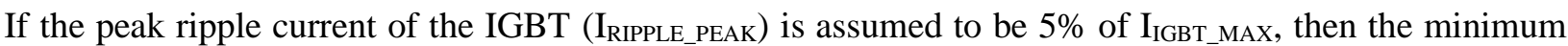
value of the coil inductance $\mathrm{L}_{\text {BоOоs }}$ in the DC-DC converter can be determined as [13],

$$
L_{\text {BOOST }} \geq \frac{V_{\text {MIN }}\left(V_{D_{-} \text {LINK }}-V_{M I N}\right)}{I_{\text {RIPPLE_PEAK }_{-} f_{\text {SW }_{-} \text {BOOST }} V_{D_{-} \text {LINK }}}} \geq 0.4080 \mathrm{mH}
$$


where $\mathrm{f}_{\mathrm{SW} \_ \text {Boost }}$ is the PWM switching frequency of the IGBT in the DC-DC converter and its value is equal to $5 \mathrm{kHz}$. Practically, $\mathrm{L}_{\text {воо }}$ is chosen as $0.5 \mathrm{mH}$ for stabilizing the simulation in all control modes. On the other hand, the power oscillations at the PV array output due to changes in solar irradiance and weather temperature are reduced by a decoupling capacitor $\mathrm{C}_{\mathrm{PV}}$. This capacitor is usually replaced between the output of the PV array and the input of the DC-DC converter in a multistage power processing configuration for smooth energy flow [14]. $\mathrm{C}_{\mathrm{PV}}$ is determined as follows [15],

$$
C_{P V}=\frac{0.5 D_{M A X} V_{D C_{-} L I N K}}{4 V_{\text {RIPPLE }_{-} \text {PEAK }} f_{S W_{-} \text {BOOST }}^{2} L_{\text {BOOST }}}=128 \mu \mathrm{F} .
$$

\subsection{Link Capacitor Design}

The DC link capacitor at the input of the inverter reduces the ripple voltage to provide almost constant DC voltage at the inverter input. At first, the peak value of the inverter output current is calculated as,

$$
I_{I N V_{-} P E A K}=\left(\sqrt{2} P_{\text {Plant }}\right) \div\left(3 V_{\text {PHAASE_RMS }_{-} \eta_{I N V}}\right)=603 \mathrm{~A}
$$

where $\eta_{I N V}$ is the minimum estimated inverter efficiency and its value is equal to $85 \%$. Then, the average of the inverter output current is calculated as,

$$
I_{I N V_{-} A V G}=0.9 I_{I N V_{-} R M S}=384 \mathrm{~A} .
$$

The peak ripple voltage the DC link is estimated as,

$$
V_{\text {RIPPLE_ }_{-} \text {PAK }}=0.05 V_{D_{-} L I N K}=35 \mathrm{~V} \text {. }
$$

Since the maximum allowable ripple is usually $5 \%$ of the rated value. Finally, the DC link capacitance $\mathrm{C}_{\mathrm{DC} \_ \text {LINK }}$ is found as follows where $\omega=314 \mathrm{rad} / \mathrm{s}$ is the rated angular frequency of the grid [16],

$$
C_{D C_{-} L I N K} \geq \frac{I_{I N V_{-} A V G}}{2 \omega V_{\text {RIPPLE_-PEAK }}} \geq 17.461 \mathrm{mF} .
$$

\subsection{LCL Filter Design}

There are usually many types of passive components/power electronic systems that have to be designed when connecting the PV system to the utility grid. This is due to many factors that affect the performance and efficiency of the overall system, such as temperature, solar irradiance, the characteristics of the connected loads, and the effects of other derating factors. These factors can possibly disturb the performance of the grid-connected PV systems. Of all of these, transformers and filters are generally designed. The transformers are used for coupling the output of the PV system and the grid especially when the voltage levels are different. Besides transformers, passive filters are also utilized to eliminate or reduce the switching harmonics resulted from the power semiconductor switching in power electronic converters [17]. There are many types of these filters available, such as L, LC and LCL types [18]. These filters are designed according to the requirements of the grid connection, characteristics of the designed system as well as the desired characteristics of the output current and voltage magnitudes. In this study, LCL filter with a passive damping feature has been chosen due to its many advantages [19]. The advantages of LCL filter over L and LC type filters are using small inductance with reduced voltage drop, reduced capacitor inrush current, and lower harmonic content. There are four components in an LCL filter. The inverter side inductor is represented as $\mathrm{L}_{\text {inv }}$, the grid side inductor is represented as $\mathrm{L}_{\text {Grid }}$, the filter capacitor is represented as $\mathrm{C}_{\mathrm{f}}$, and the damping resistor is represented as $\mathrm{R}_{\mathrm{f}}$ for each phase. The filter capacitor with its minimum value is calculated as $[20,21]$; 


$$
\begin{aligned}
& C_{f}=\frac{\lambda \times P_{\text {RATED }}}{V_{\text {LINE }}^{2} \times \omega_{\text {Grid }}}, \\
& C_{f}=\frac{0.05 \times 250000}{400^{2} \times 314}=2.2488 \times 10^{-4} \text { Farad } .
\end{aligned}
$$

The value of $\lambda$ is taken as 0.05 [20]. In this equation, $\mathrm{P}_{\mathrm{RATED}}$ is the power of whole PV array which is 250 $\mathrm{kW}, \mathrm{V}_{\mathrm{LINE}}$ is the rms value of line-to-line voltage and $\omega_{\text {Grid }}$ is the angular frequency of the grid. $\omega_{\text {Grid }}$ is taken as $314 \mathrm{rad} / \mathrm{sec}$ and $\mathrm{V}_{\text {LINE }}$ is taken as $400 \mathrm{~V}$. The $3 \times 10^{-4} \mathrm{~F}$ value has been accepted as capacitor value of the LCL type of filter for classical PI current controller, $6 \times 10^{-4} \mathrm{~F}$ value has been accepted as capacitor value of the LCL type of filter for SMC, and $6 \times 10^{-4} \mathrm{~F}$ value has been accepted as capacitor value of the LCL type of filter for MPC technique. The value of the inverter side inductor is calculated for SMC current controller as [22];

$$
L_{I N V}=\frac{V_{D C_{-} L I N K}}{6 \times f_{\text {SWITCHING }} \times \Delta I_{L \max }}
$$

where, $\mathrm{V}_{\mathrm{DC} \_ \text {LINK }}$ is the reference $\mathrm{DC}$ link voltage which is $700 \mathrm{~V}, \mathrm{f}_{\mathrm{SWITCHING}}$ is the switching frequency of the inverter which is $2500 \mathrm{~Hz}$, and $\Delta \mathrm{I}_{\mathrm{Lmax}}$ is the maximum ripple current of the inverter. The inverter side inductor is calculated for discrete time MPC with finite switching states current control technique and for classical PI inverter current control technique as [23];

$$
L_{I N V}=\frac{V_{D C_{-} L I N K}}{16 \times f_{\text {SWITCHING }} \times \Delta I_{L \max }} .
$$

$\Delta \mathrm{I}_{\mathrm{Lmax}}$ has been calculated as $10 \%$ of the current ripple as [24];

$$
\begin{aligned}
& I_{\text {max }}=\frac{P_{\text {Rated }} \times \sqrt{2}}{3 \times V_{\text {Phase }}}=\frac{250000 \times \sqrt{2}}{3 \times 230}=512.396 \mathrm{~A}, \\
& \Delta I_{L \max }=0.1 \times I_{\text {max }}=51.23 \mathrm{~A}
\end{aligned}
$$

where, $\mathrm{I}_{\max }$ is the output current of the inverter, $\mathrm{P}_{\text {Rated }}$ is the real power of the whole $\mathrm{PV}$ array which has 250 $\mathrm{kW}$ of real power, and $\mathrm{V}_{\text {Phase }}$ is the RMS value of the output phase voltage of the inverter. The inverter side inductor in the LCL filter for SMC scheme is determined as;

$$
L_{\text {inv }}=\frac{V_{D C_{-} L I N K}}{6 \times f_{\text {SWITCHING }} \times \Delta I_{L \max }}=\frac{700}{6 \times 2500 \times 51.23}=9.1 \times 10^{-4} \mathrm{H} .
$$

The inverter side inductor in the LCL filter for discrete time MPC with finite switching states current control technique and classical PI inverter current control technique is determined as;

$$
L_{\text {inv }}=\frac{V_{D_{-} \_L N K}}{16 \times f_{\text {SWITCHING }} \times \Delta I_{L \max }}=\frac{700}{16 \times 2500 \times 51.23}=3.41 \times 10^{-4} \mathrm{H} .
$$

The grid side inductor and the damping resistor are calculated according to the ranges of the resonance frequency of the system [25]. The interval of the resonance frequency is obtained as [19]; 
$10 \times f_{\text {Grid }}<f_{\text {Re sonance }}<0.5 \times f_{\text {SWITCHING }}$.

Therefore, the interval of the resonance frequency of the system is given as;

$10 \times 50 \mathrm{~Hz}<f_{\text {Re sonance }}<0.5 \times 2500 \mathrm{~Hz}$

where, $f_{\text {Grid }}=50 \mathrm{~Hz}$ is the grid frequency, and $f_{\text {Resonance }}$ is the resonance frequency of the system. The grid side inductor is then calculated according to the determined suitable resonance frequency as;

$$
f_{\text {Re sonance }}=\frac{1}{2 \pi} \times \sqrt{\frac{L_{i n v}+L_{\text {grid }}}{L_{i n v} \times L_{\text {grid }} \times C_{f}}}
$$

For each control scheme, the filter parameters are designed separately. The grid side inductor is determined using $807 \mathrm{~Hz}$ as resonance frequency, $9.1 \times 10^{-4} \mathrm{H}$ as inverter side inductor, and $6 \times 10^{-4} \mathrm{~F}$ as filter capacitor for SMC inverter current control technique;

$$
\begin{aligned}
& f_{\text {Re sonance }}=\frac{1}{2 \pi} \times \sqrt{\frac{9.1 \times 10^{-4} H+L_{\text {grid }}}{9.1 \times 10^{-4} H \times L_{\text {grid }} \times 6 \times 10^{-4} F}}, \\
& L_{\text {grid }}=2.1 \times 10^{-4} H .
\end{aligned}
$$

The grid side inductor is determined using $726 \mathrm{~Hz}$ as resonance frequency, $4 \times 10^{-4} \mathrm{H}$ as inverter side inductor, and $6 \times 10^{-4} \mathrm{~F}$ as filter capacitor for MPC technique;

$$
\begin{aligned}
& f_{\text {Re sonance }}=\frac{1}{2 \pi} \times \sqrt{\frac{4 \times 10^{-4} H+L_{\text {grid }}}{4 \times 10^{-4} H \times L_{\text {grid }} \times 6 \times 10^{-4} F}}, \\
& L_{\text {grid }}=1 \times 10^{-4} \mathrm{H} .
\end{aligned}
$$

The grid side inductor is determined using $1287 \mathrm{~Hz}$ as resonance frequency, $3.4 \times 10^{-4} \mathrm{H}$ as inverter side inductor, and $6 \times 10^{-4} \mathrm{~F}$ as filter capacitor for classical PI inverter current control technique;

$$
\begin{aligned}
& f_{\text {Re sonance }}=\frac{1}{2 \pi} \times \sqrt{\frac{3.4 \times 10^{-4} H+L_{\text {grid }}}{3.4 \times 10^{-4} H \times L_{\text {grid }} \times 3 \times 10^{-4} F}}, \\
& L_{\text {grid }}=6 \times 10^{-5} \mathrm{H} .
\end{aligned}
$$

The damping resistance is calculated according to the determined resonance frequency as [26];

$$
R_{f}=\frac{2 Z}{\omega_{\text {Re sonance }} \times C_{f}}
$$

where, $\omega_{\text {Re sonance }}$ is the resonance angular frequency. $\mathrm{Z}$ represents the damping factor of the filter which is between 0 and 1 . The damping resistance of the LCL is designed as $0.30 \Omega$ for the three inverter control techniques. In work, since three different control schemes are used as inverter current control, in order to 
obtain the optimum performance, LCL filter parameters for each control scheme are designed and listed in Table 2 [27].

\subsection{DC-DC Converter Control}

DC-DC converter control regulates the desired input DC voltage for the inverter by boosting the output voltage of the PV array with MPPT algorithm which is based on incremental conductance with integral regulator. At first, the voltage V and the current I of the PV array is sampled and an integrator minimizes the error signal generated by comparing instantaneous conductance (I/V) to the incremental conductance $(\Delta \mathrm{I} / \Delta \mathrm{V})$. Finally, the output of the integrator generates the required duty cycle $\mathrm{D}$. Then $\mathrm{D}$ is compared to a saw tooth signal with a frequency of $\mathrm{f}_{\mathrm{SW} \_ \text {_ооотт }}$ in the PWM generator to produce the firing pulses for the IGBT in the DC-DC converter. By this way, the output of the DC-DC converter is regulated to ensure maximum power generation from the sun.

Table 2. Optimized LCL filter parameters for each control scheme

\begin{tabular}{|l|l|l|l|}
\hline \multirow{2}{*}{ LCL Filter Parameters } & Value and Unit & \\
\cline { 2 - 4 } & PI Controller & SMC & MPC \\
\hline Inverter side resistance, $\mathrm{R}_{1}$ & $0.0005 \Omega$ & $0.0005 \Omega$ & $0.0005 \Omega$ \\
\hline Inverter side inductance, $\mathrm{L}_{1}$ & $340 \mu \mathrm{H}$ & $700 \mu \mathrm{H}$ & $400 \mu \mathrm{H}$ \\
\hline Grid side resistance, $\mathrm{R}_{2}$ & $0.0005 \Omega$ & $0.0005 \Omega$ & $0.0005 \Omega$ \\
\hline Grid side inductance, $\mathrm{L}_{2}$ & $60 \mu \mathrm{H}$ & $71.5 \mu \mathrm{H}$ & $100 \mu \mathrm{H}$ \\
\hline Damping resistance, $\mathrm{R}_{3}$ & $0.079 \Omega$ & $0.3 \Omega$ & $0.3 \Omega$ \\
\hline Capacitance, $\mathrm{C}_{3}$ & $300 \mu \mathrm{F}$ & $600 \mu \mathrm{F}$ & $600 \mu \mathrm{F}$ \\
\hline
\end{tabular}

\subsection{NPC Inverter Control}

Two time-domain nonlinear control methods, such as SMC and discrete time MPC with finite set model are applied for the current control of the NPC inverter. Later on, these control approaches are compared with classical PI current control scheme based on decoupling function. SMC and MPC control schemes are respectively based on dq and alfa-beta coordinate transformation. In principle, the NPC inverter control scheme calculates the current and voltage reference signals and governs the switching signals of the semiconductor switches for the control of active and reactive power flow through the NPC inverter. With this respect, active and reactive power can be controlled to regulate the DC link voltage of the NPC inverter and for unity power factor operation, respectively. In all controller designs, the controller parameters are optimized by trial-and-error approach. The block diagram model of the control schemes is depicted in Figure 3. In either control scheme, a PI controller as the outer control loop is addressed to regulate the DC link voltage of the NPC inverter at the reference value of $700 \mathrm{~V}$. The output of this controller is the d-axis reference current $\mathrm{I}_{\mathrm{d}_{\_} \text {ref, }}$, to be sent to the inner control loops in each control mode for the calculation of the reference voltage for the NPC inverter. Once the reference voltage for the NPC inverter is obtained, the gate signals for the IGBT switches are generated based on PWM method. A $2500 \mathrm{~Hz}$ triangular carrier waveform is used in the PWM method used for SMC and PI current control schemes. The synchronization of the overall PV system with the grid is established with a PLL that estimates the phase angle of phase-a in the grid, wt. Besides, PLL measurement, all voltage and current measurements are taken at the point of common coupling (PCC) of the system, which is the low voltage side of the coupling transformer. In each control scheme, $\mathrm{I}_{\mathrm{q}_{-} \text {ref }}=0$ condition is settled for unity power factor operation of the overall PV system. As seen in Figure 3, the DC voltage controller is the outer control loop which is used to obtain the desired and constant DC link voltage for proper inverter operation. This condition is necessary since NPC inverter used in this study is a voltage source inverter type that needs constant DC voltage to operate. Besides DC voltage controller, the PI control technique is also implemented to regulate the d-and q-axis inverter currents as shown in Figure 3. In PI current control scheme, when calculating the gains, $\mathrm{L}_{\text {filter }}=\mathrm{L}_{1}+\mathrm{L}_{2}$ is used as the per unit inductance of the LCL filter. The PI controller parameters are designed to give satisfactory transient and steady-state performance $[28,29]$. The required power values for the grid are supplied by the PV arrays but sometimes the injected power does not match with the required one due to the natural conditions, such as, solar irradiation, ambient temperature, and other derating factors. Under these conditions, the voltage 
control loop manages the DC link voltage and modifies the active and reactive current or active and reactive power according to the requirements of the grid and loads [30]. According to this control system, the reference active current is obtained by passing the difference between the actual and the reference DC link voltage through PI controller. Then the output of the PI controller is taken as the reference active current. The reactive current reference is set to zero for satisfying unity power factor operation. The details of the DC voltage controller model is shown in Figure 4.

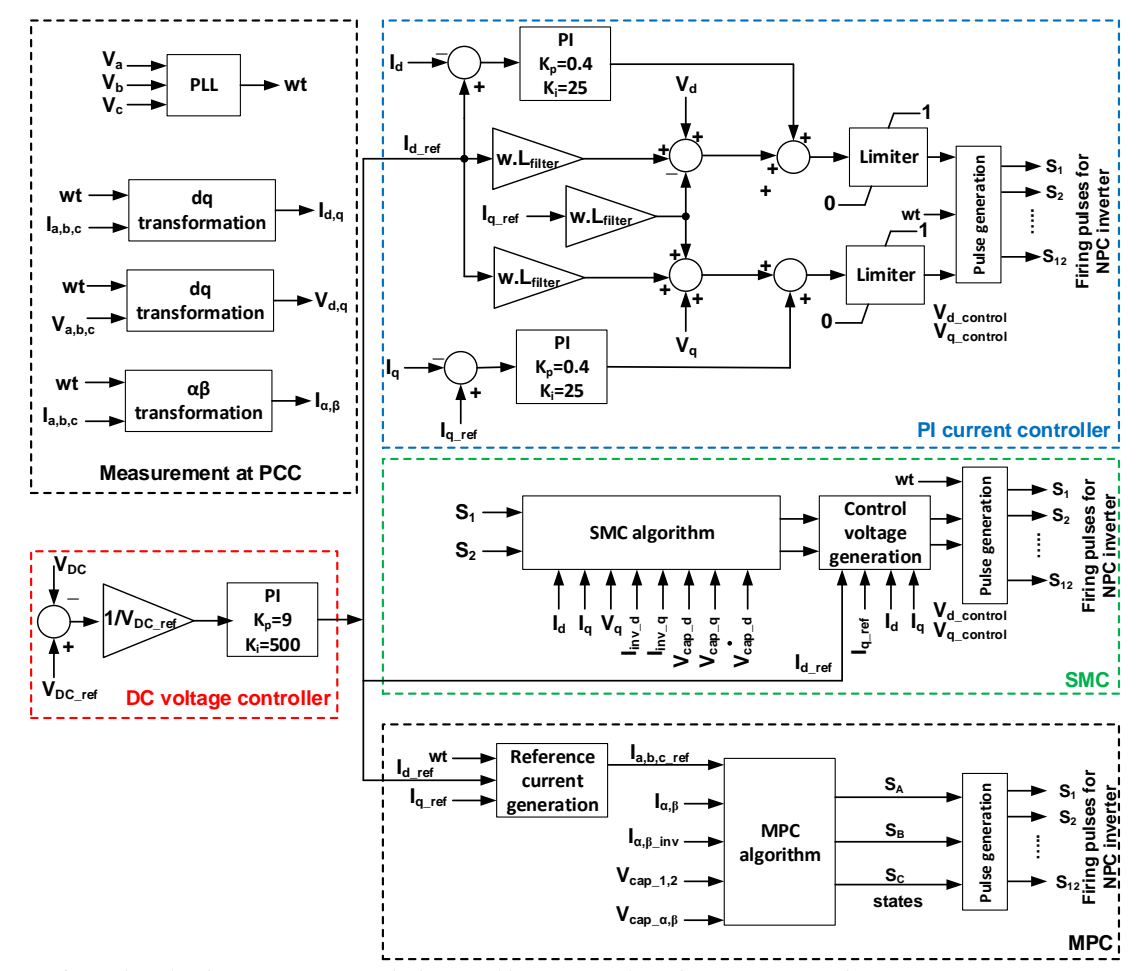

Figure 3. Block diagram model of all control schemes used in NPC inverter control

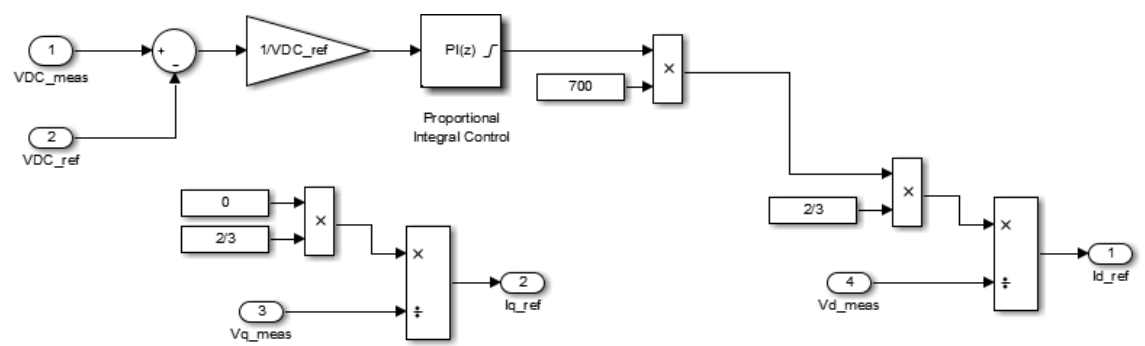

Figure 4. DC voltage controller used in different control schemes (PI control, SMC, MPC)

\subsubsection{SMC Scheme}

Sliding mode control (SMC) is a nonlinear, deterministic and variable structure_method that depends on state-dependent switching feedback control which purposely alters the system structure. A set-valued control signal forces the system to slide along a cross-section of the system's normal response to change the dynamics of the system. SMC is attractive due to quick convergence and robustness properties. In this work, SMC is applied for the current control of the NPC inverter, while the DC voltage controller is the same as in PI current control. The SMC design requires the mathematical model of the NPC inverter. After Park's transformation, the $\mathrm{dq}$ components of inverter output current ( $\mathrm{I}_{\text {inv_d }}$ and $\mathrm{I}_{\text {inv_q }}$ ) in terms of dq components of inverter output voltage $\left(\mathrm{V}_{\text {inv_d }}\right.$ and $\left.\mathrm{V}_{\text {inv_q }}\right)$ and those of $\mathrm{C}_{3}$ in $L C L$ filter $\left(\mathrm{V}_{\text {cap_d }}\right.$ and $\left.\mathrm{V}_{\text {cap_q }}\right)$ are found as,

$L_{1}\left[\begin{array}{c}\dot{I}_{i n v_{-} d} \\ \dot{I}_{i n v_{-} q}\end{array}\right]=\left[\begin{array}{c}V_{i n v_{-} d} \\ V_{i n v_{-} q}\end{array}\right]-\left[\begin{array}{c}V_{c a p_{-} d} \\ V_{c a p_{-} q}\end{array}\right]-1.5 w L_{1}\left[\begin{array}{c}-I_{i n v_{-} q} \\ I_{i n v_{-} d}\end{array}\right]$ 


$$
\begin{gathered}
L_{2}\left[\begin{array}{l}
\dot{I}_{d} \\
\dot{I}_{q}
\end{array}\right]=\left[\begin{array}{l}
V_{c a p_{-} d} \\
V_{c a p_{-} q}
\end{array}\right]-\left[\begin{array}{c}
V_{d} \\
V_{q}
\end{array}\right]-1.5 w L_{2}\left[\begin{array}{c}
-I_{q} \\
I_{d}
\end{array}\right] \\
C_{3}\left[\begin{array}{c}
\dot{V}_{c a p_{-} d} \\
\dot{I}_{c a p_{-} q}
\end{array}\right]=\left[\begin{array}{c}
I_{i n v_{-} d} \\
I_{i n v_{-} q}
\end{array}\right]-\left[\begin{array}{c}
I_{d} \\
I_{q}
\end{array}\right]-1.5 w C_{3}\left[\begin{array}{c}
-V_{c a p_{-} q} \\
V_{c a p_{-} d}
\end{array}\right] .
\end{gathered}
$$

In SMC design, sliding surfaces $\mathrm{S}_{1}, \mathrm{~S}_{2}$ in terms of errors $e$ and their derivatives are selected to control active and reactive current of the inverter. The surface equations are linear and given as,

$$
\begin{aligned}
& S_{1}=m_{1} e_{1}+m_{2} \dot{e}_{1}+\ddot{e}_{1} \\
& S_{2}=m_{1} e_{2}+m_{2} \dot{e}_{2}+\ddot{e}_{2}
\end{aligned}
$$

where $\mathrm{m}_{1}, \mathrm{~m}_{2}$ are positive constants, $\mathrm{e}_{1}=\mathrm{I}_{\mathrm{d} \_ \text {ref }}-\mathrm{I}_{\mathrm{d}}$ and $\mathrm{e}_{2}=\mathrm{I}_{\mathrm{q} \_ \text {ref }}-\mathrm{I}_{\mathrm{q}}$. Selected surfaces should contain different values in the range between the reference and actual current values. These differences are the errors for determining the convergence condition of the controller. When $S_{1}=S_{2}=0$, the global stability of $\mathrm{SMC}$ is satisfied. The convergence condition is $\mathrm{SS}<0$ and the derivatives of the sliding surfaces are determined as,

$$
\begin{aligned}
& \dot{S}_{1}=-Y S_{1}-Z \operatorname{sign}\left(S_{1}\right) \\
& \dot{S}_{2}=-Y S_{2}-Z \operatorname{sign}\left(S_{2}\right)
\end{aligned}
$$

where $\mathrm{Y}$ and $\mathrm{Z}$ are positive constants. The final step in SMC design is to evaluate the derivatives of the errors to find the relationships between the dq components of currents and dq components of reference voltage for the inverter. The first, second, and third derivatives of errors are expressed as,

$$
\begin{aligned}
& \dot{e}_{1}=-\dot{I}_{q}=-\left[\frac{V_{c a p_{-} d}}{L_{2}}+\frac{3}{2} \omega I_{q}\right] \\
& \ddot{e}_{1}=-\left[\frac{V_{c a p_{-} d}}{L_{2}}+\frac{3}{2} \omega \dot{I}_{q}\right]=I_{d}\left[\frac{1}{C_{3} L_{2}}+\frac{9}{4} \omega^{2}\right]-\frac{3 \omega}{L_{2}} V_{c a p_{-} q}+\frac{3 \omega}{2 L_{2}} V_{q}-\frac{I_{\text {inv } d}}{L_{2} C_{3}} \\
& \dddot{e}_{1}=\dot{I}_{d}\left[\frac{1}{C_{3} L_{2}}+\frac{9}{4} \omega^{2}\right]-\frac{3 \omega}{L_{2}} \dot{V}_{c a p_{-} d}-\frac{V_{d_{-} c o n t r o l}}{L_{1} L_{2} C_{3}}+\frac{V_{c a p_{-} d}}{L_{1} L_{2} C_{3}}-\frac{3 \omega}{2 C_{3} L_{2}} I_{i n v_{-} q} \\
& \dot{e}_{2}=-\dot{I}_{q}=-\left[\frac{V_{c a p_{-} q}}{L_{2}}-\frac{3}{2} \omega I_{d}-\frac{V_{q}}{L_{2}}\right] \\
& \ddot{e}_{2}=-\left[\frac{V_{c a p_{-} q}}{L_{2}}+\frac{3}{2} \omega \dot{I}_{d}\right]=I_{q}\left[\frac{1}{C_{3} L_{2}}+\frac{9}{4} \omega^{2}\right]+\frac{3 \omega}{L_{2}} V_{c a p_{-} d}-\frac{I_{i n v_{-} q}}{L_{2} C_{3}} \\
& \dddot{e}_{2}=\dot{I}_{q}\left[\frac{1}{C_{3} L_{2}}+\frac{9}{4} \omega^{2}\right]+\frac{3 \omega}{L_{2}} \dot{V}_{c a p_{-} d}-\frac{V_{q_{-} c o n t r o l}}{L_{1} L_{2} C_{3}}+\frac{V_{c a p_{-} q}}{L_{1} L_{2} C_{3}}+\frac{3 \omega}{2 C_{3} L_{2}} I_{\text {inv } d} .
\end{aligned}
$$


Using the equations for $\dddot{e}_{1}$ and $\dddot{e}_{2}$ the general control voltages in the dq coordinates are obtained as follows,

$$
\begin{gathered}
V_{d_{-} \text {control }}=\left[\begin{array}{l}
\left.\left[\frac{V_{c a p_{-} d}}{L_{2}}+\frac{3}{2} \omega I_{q}\right]\left[\frac{1}{C_{3} L_{2}}+\frac{9}{4} \omega^{2}\right]-\frac{3 \omega}{L_{2}} \dot{V}_{c a p_{-} d}-\frac{V_{d_{-} \text {control }}}{L_{1} L_{2} C_{3}}+\frac{V_{c a p_{-} d}}{L_{1} L_{2} C_{3}}-\right] L_{1} L_{2} C_{3} \\
2 C_{3} L_{2}
\end{array}\right] \\
V_{q_{-} \text {control }}=\left[\begin{array}{l}
\left.\left[\frac{V_{c a p_{-} q}}{L_{2}}-\frac{3}{2} \omega I_{d}-\frac{V_{q}}{L_{2}}\right]\left[\frac{1}{C_{3} L_{2}}+\frac{9}{4} \omega^{2}\right]+\frac{3 \omega}{L_{2}} \dot{V}_{c a p_{-} d}-\frac{V_{q_{-} \text {control }}}{L_{1} L_{2} C_{3}}+\right] L_{1} L_{2} C_{3} . \\
\frac{V_{c a p_{-} d}}{L_{1} L_{2} C_{3}}+\frac{3 \omega}{2 C_{3} L_{2}} I_{i n v_{-} d}-\dot{S}_{2}
\end{array}\right]
\end{gathered}
$$

After obtaining the reference power values by using the respective controller, the injected active power into the grid can be written as follows in dq0 coordinate system [31,32];

$$
P=\frac{3}{2} \times\left[V_{\text {grid } \_} \times I_{\text {grid_d }}+V_{\text {grid }_{-} q} \times I_{\text {grid }_{-} q}\right]
$$

where, $\mathrm{V}_{\text {grid_d }}$ and, $\mathrm{V}_{\text {grid_q }}$ are d- and q-axis of the grid voltage, respectively, $\mathrm{I}_{\text {grid_d }}$ and, $\mathrm{I}_{\text {grid_d }}$ are d- and qaxis of the reference grid current, respectively. The reference values of active and reactive power injections into the grid are obtained as follows [33];

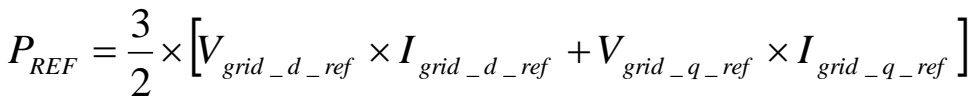

$$
\begin{aligned}
& Q_{R E F}=\frac{3}{2} \times\left[V_{\text {grid_q_ef }} \times I_{\text {grid_d_dref }_{-}}-V_{\text {grid_d_ref }} \times I_{\text {grid_q_ref }}\right]
\end{aligned}
$$

where, , $\mathrm{V}_{\text {grid_d_ref }}$ and, $\mathrm{V}_{\text {grid_q__ref }}$ values are d- and q-axis of reference voltage, respectively, $\mathrm{I}_{\text {grid_d_ref }}$ and, $\mathrm{I}_{\text {grid_q_ref }}$ are d- and q-axis of reference grid current, respectively. Since the reactive power injection is not desired, the q-axis reference current is set to zero to ensure unity power factor operation. Thus, the reference active power equation is simplified as follows;

$$
P_{R E F}=\frac{3}{2} \times\left[V_{\text {grid_d } d_{-} r e f} \times I_{g_{\text {grid_d }} d_{-} r e f}\right] .
$$

From Equation (50), the reference of d-axis grid current is written as follows;

$$
I_{\text {grid_d_ref }}=\frac{2}{3 \times V_{\text {grid_d_ref }}} \times P_{R E F} \text {. }
$$

\subsubsection{MPC Scheme}

Model predictive control (MPC) is a model-based control policy based on dynamic model of the system and the update of the optimal control actions. MPC predicts the system performance and choose the best control act depending upon the current system states. In MPC, a finite time-horizon is optimized while preserving future time slots, thereby system limitations can be taken into account. In this work, discrete 
time MPC with finite switching states for the NPC inverter is adopted to predict the voltage and current magnitudes and cope with the coupled control problem of inverter current control scheme. DC voltage controller is the same as in PI current control. In NPC inverter topology, there are two series connected capacitors $\left(\mathrm{C}_{\mathrm{DC}_{-} \mathrm{LINK}}\right)$ at the DC side as shown in Figure 1 . There are 27 switching states in three-phase NPC inverter to produce three voltage levels $\left( \pm \mathrm{V}_{\mathrm{DC}_{-} \text {LINK }}, 0\right)$ at the output. So, the inverter output voltage is determined according to these switching states. The relationship between the inverter output voltage $V_{\text {inv }}$ per phase, determined by the switching state $\mathrm{S}$ and DC link voltage $\mathrm{V}_{\mathrm{DC} \_ \text {LINK }}$ is expressed as,

$V_{i n v}=V_{D C_{-} L I N K} S$

Figure 5 shows the model of three-phase three-level NPC inverter used in this study. Two DC link capacitors which are connected in series such as $C_{D C_{-} 1}$ and $C_{D C_{-} 2}$ divide the DC-link voltage into three DC voltage leves such as $+\mathrm{V} \_\mathrm{dc} / 2,0$ and $-\mathrm{V} \_\mathrm{dc} / 2$ [34]. The point $\mathrm{N}$ is called as "neutral point" that occurs in the middle of the DC link line. There are four controllable switches in each leg of the three-phase threelevel NPC inverter. There are finite numbers of switch states in this inverter type and these switch states are listed in Table 3 for each phase, respectively. The NPC inverter has 27 switch states since there are three legs and three phases in the power circuit. Although there are 27 switch states, 8 switch states of them are same. Therefore, 19 of these switch states are different from each other and used in discrete time MPC scheme with finite switching states current control mechanism [35]. After determining the finite number of switching states, the inverter output voltage values are represented by multiplication of DC link voltage that is represented with VDC with one switching condition of the switching states for calculating the predicted inverter side current values [36]. The inverter output voltages are written in general form as follows;

$V_{x_{-} i n v}=V_{D C} S_{y} \quad \mathrm{x}=\mathrm{a}, \mathrm{b}, \mathrm{c}$ and $\mathrm{y}=\mathrm{A}, \mathrm{B}, \mathrm{C}$.

The inverter output voltages are written for each phase as follows;

$$
\begin{aligned}
& V_{a_{-} i n v}=V_{D C} S_{A}, \\
& V_{b_{-} i n v}=V_{D C} S_{B}, \\
& V_{c_{-} i n v}=V_{D C} S_{C} .
\end{aligned}
$$

After Clarke transformation, the dynamic equations of the inverter connected to LCL filter is obtained as,

$$
\begin{aligned}
& V_{\alpha_{-} i n v}=L_{1} \frac{d I_{\alpha_{-} i n v}}{d t}+R_{1}\left(I_{\alpha_{-} i n v}-I_{\alpha}\right)+V_{c q p_{-} \alpha} \\
& V_{\beta_{-} i n v}=L_{1} \frac{d I_{\beta_{-} i n v}}{d t}+R_{1}\left(I_{\beta_{-} i n v}-I_{\beta}\right)+V_{c q p_{-} \beta}
\end{aligned}
$$

where subscript $\alpha, \beta$ denote alfa and beta components, $\mathrm{I}_{\text {inv }}$ and $\mathrm{I}$ is the inverter output current and grid side current at the PCC, respectively. The predicted values of inverter side currents according to the varying inverter output voltage are obtained as,

$$
I_{\alpha_{-} \text {predicted }}(k+1)=I_{\alpha_{-} i n v}(k)+\left(\frac{T_{S}}{L_{1}}\right)\left[V_{\alpha_{-} i n v}(k)-V_{\text {cap_ } \alpha}(k)-R_{1_{-} \alpha}\left(I_{\alpha_{-} i n v}(k)-I_{\alpha_{-} \text {grid }}(k)\right)\right]
$$


$I_{\beta_{-} \text {predicted }}(k+1)=I_{\beta_{-} i n v}(k)+\left(\frac{T_{S}}{L_{1}}\right)\left[V_{\beta_{-} i n v}(k)-V_{c a p_{-} \beta}(k)-R_{1_{-} \beta}\left(I_{\beta_{-} i n v}(k)-I_{\beta_{-} \text {grid }}(k)\right)\right]$

where $T_{S}$ is the sampling period. The prediction is handled by forward Euler approximation. Finally, the best switching states are obtained by minimizing a cost function $\mathrm{g}$ based on the error between the reference and predicted output current of the inverter. Hence the best switching state selection is obtained when $\mathrm{g}$ is equal to 0

$g=\left|I_{\alpha_{-} \text {ref_inv }}(k)-I_{\alpha_{-} \text {predicted }}(k+1)\right|+\left|I_{\beta_{-} \text {ref_inv }}(k)-I_{\beta_{-} \text {predicted }}(k+1)\right|$.

In MPC scheme, like in other control approaches, the reference reactive power is adjusted to zero in order to satisfy unity power factor condition for the grid-connected PV system. The reference active power is obtained from the output of the voltage controller unit. These generated reference current and power values are obtained in $\mathrm{dq} 0$ coordinate system, so their values are used by converting them into the stationary reference coordinate system ( $\alpha \beta 0$ coordinates) for discrete time MPC with finite switching states current control technique.

\section{THE RESEARCH FINDINGS AND DISCUSSION}

The simulation results of the 250-kW grid-connected PV array which is shown in Figure 1 are presented in this section. At first, the starting dynamics of the controllers as shown in Figure 6 are investigated for fixed weather condition. The irradiance and temperature are set to $1000 \mathrm{~W} / \mathrm{m}^{2}$ and $25^{\circ} \mathrm{C}$, respectively. It is seen that after a transient at the output power in all cases, the controller settles the output power at steady-state of $250 \mathrm{~kW}$. During starting, PI controller gives the minimum undershoot, while SMC and MPC produce stronger undershoot for the output power. However, the overshoots are practically same for all controllers. It is seen that after a transient at the output power in all cases, the stabilization in the variables is observed earlier in the systems controlled by SMC and MPC techniques. It means that the settling time of SMC and MPC techniques is very smaller than the settling time of the PI control technique. Figure 7 shows the PCC current waveform of phase-a during starting when different controllers are activated for fixed weather condition. It is observed that the SMC scheme causes the current waveform to have some noise but this noise is very little. Apart from this point, the current waveforms obtained in each control scheme are practically similar along the simulation time.

Table 3. The switching states for three-phase three-level NPC inverter

\begin{tabular}{|l|l|l|l|l|l|l|l|l|l|l|l|l|l|l|}
\hline \multicolumn{1}{|c|}{ Phase A switching states } & \multicolumn{4}{c|}{ Phase B switching states } \\
\hline $\mathrm{S}_{\mathrm{A}}$ & $\mathrm{S}_{\mathrm{A} 1}$ & $\mathrm{~S}_{\mathrm{A} 2}$ & $\mathrm{~S}_{\mathrm{A} 3}$ & $\mathrm{~S}_{\mathrm{A} 4}$ & $\mathrm{~S}_{\mathrm{B}}$ & $\mathrm{S}_{\mathrm{B} 1}$ & $\mathrm{~S}_{\mathrm{B} 2}$ & $\mathrm{~S}_{\mathrm{B} 3}$ & $\mathrm{~S}_{\mathrm{B} 4}$ & $\mathrm{~S}_{\mathrm{C}}$ & $\mathrm{S}_{\mathrm{C} 1}$ & $\mathrm{~S}_{\mathrm{C} 2}$ & $\mathrm{~S}_{\mathrm{C} 3}$ & $\mathrm{~S}_{\mathrm{C} 4}$ \\
\hline 1 & 1 & 1 & 0 & 0 & 1 & 1 & 1 & 0 & 0 & 1 & 1 & 1 & 0 & 0 \\
\hline 0 & 0 & 1 & 1 & 0 & 0 & 0 & 1 & 1 & 1 & 0 & 0 & 1 & 1 & 0 \\
\hline-1 & 0 & 0 & 1 & 1 & -1 & 0 & 0 & 1 & 1 & -1 & 0 & 0 & 1 & 1 \\
\hline
\end{tabular}




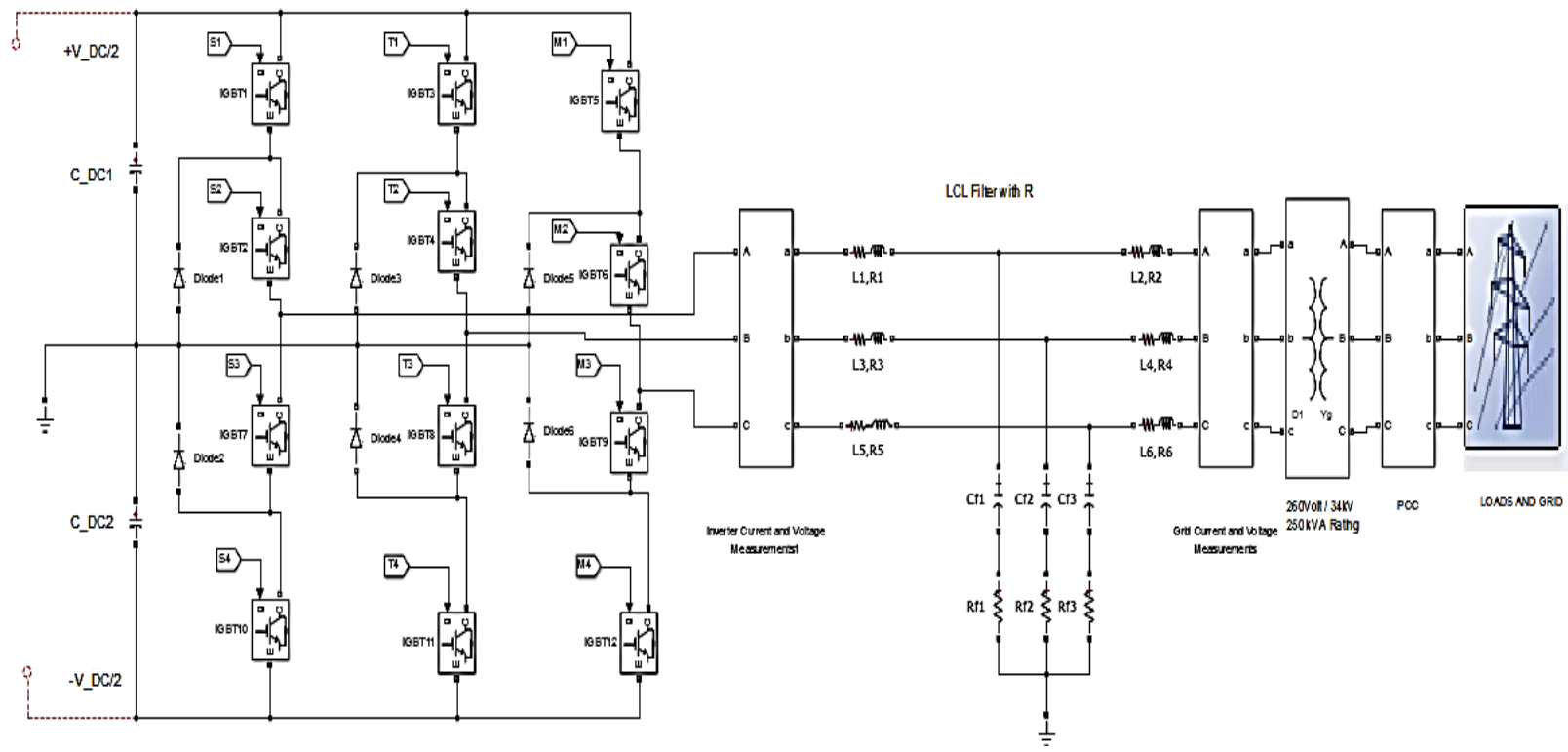

Figure 5. Matlab Simulink model of three-phase three-level NPC inverter

Figure 8 shows the dynamic performance of the DC voltage controller during starting for different controller activations for the NPC inverter. As observed, the DC voltage of the inverter reaches to the reference of $\mathrm{V}_{\mathrm{DC} \_ \text {LINK }}=0$ for all control modes and all the controllers in the system gives satisfactory stable response. Although the overshoot observed in case of SMC scheme is sharper, the SMC and MPC scheme settle the DC link voltage faster than PI scheme. As a next case study, the performance of each controller is examined and compared with each other against changing irradiance and temperature conditions, as shown in Figure 9. Figure 10 and 11 respectively shows the simulated power generation of the PV system and PCC current waveform of phase-a for different control modes under changing weather conditions. Although, almost all controllers produce similar performance when irradiance changes, PI control and MPC schemes have slightly better steady-state performance for the temperature change when compared to SMC scheme. It is observed that the SMC scheme causes the current waveform to have some noise but this noise is very little. Since the power generation of the PV system strongly depends on irradiance of the sun, at around $\mathrm{t}=1.2 \mathrm{~s}$, the power generation and hence the PCC current temporarily reduces to minimum for a sharp reduction in irradiance. Regulating the DC link voltage is essential for the proper operation of the inverter in the PV system, particularly when weather conditions alter. The performance of the DC voltage controller is depicted in Figure 12 for each control mode proposed for the inverter current control. It is clearly seen that the DC voltage controller operates stable and robust against changing weather conditions in each control scheme. The DC link voltage of the NPC inverter when different controllers are activated under changing weather conditions is depicted in Figure 13 for each control mode and it is clearly seen that the DC link voltage of the NPC inverter operates stable and robust against changing weather conditions in each control scheme. The total harmonic distortion (THD) obtained under each control system is measured and given in Table 4. The minimum THD is observed when the system is controlled by MPC technique. The maximum THD is observed when the system is controlled by classical PI control technique. According to the THD comparison, the best result is obtained when the system is controlled by MPC technique.

Table 4. THD values of each control techniques under grid connected condition

\begin{tabular}{|l|l|l|}
\hline Control Technique & Fundamental $(50 \mathrm{~Hz})$ & THD \\
\hline MPC & $5.948 \%$ & $0.30 \%$ \\
\hline SMC & $5.952 \%$ & $2.44 \%$ \\
\hline PI Control & $5.976 \%$ & $2.72 \%$ \\
\hline
\end{tabular}

\section{CONCLUSION}

Grid-connected PV based renewable energy systems are key elements for today's and future smart grids to provide clean energy to everyone. In this study, $1 \mathrm{MW}$ rated PV system connected to medium voltage 
distribution power system is planned and designed in Matlab Simulink. This system consists of four identical $250 \mathrm{~kW}$ PV arrays, connected in parallel to the grid via transformers and filtering. To verify the design, out of four identical PV arrays, the design procedure of only one of them is mentioned and simulated for the sake of simplicity. The simulation model consists of one PV array, DC-DC converter to raise the output voltage of the PV array, DC link, NPC inverter, LCL filter, and coupling transformer. The MPPT algorithm based on incremental conductance with integral regulator is applied to the DC-DC converter control loop to increase the captured power from the sun. Three different control schemes, namely, PI control, SMC, and MPC for the inverter current control function, based on coordinate transformations, are proposed and compared under fixed and changing weather conditions. In order to optimize the gridconnected operation, LCL filter parameters for each control mode are separately designed to efficiently couple the inverter to the grid. It is observed both linear and nonlinear current control schemes of the inverter operate stable and almost give similar performances in particular for the steady-state conditions. However, the dynamic performances of the controllers are different, especially during system starting.
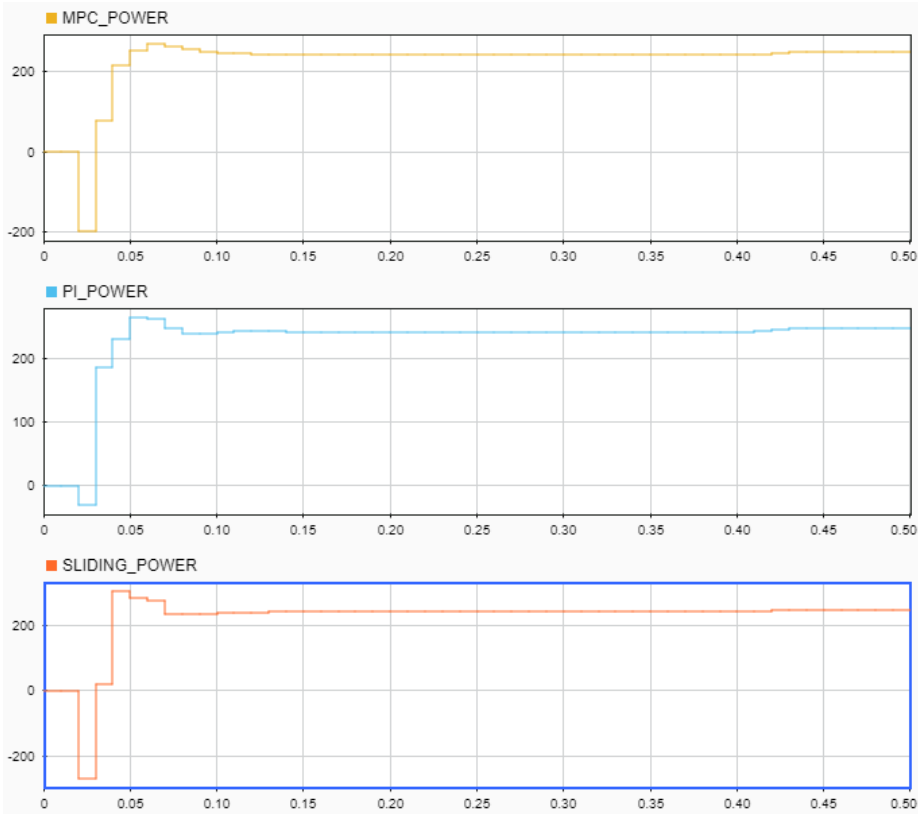

Figure 6. Starting dynamics of each controller at fixed weather condition
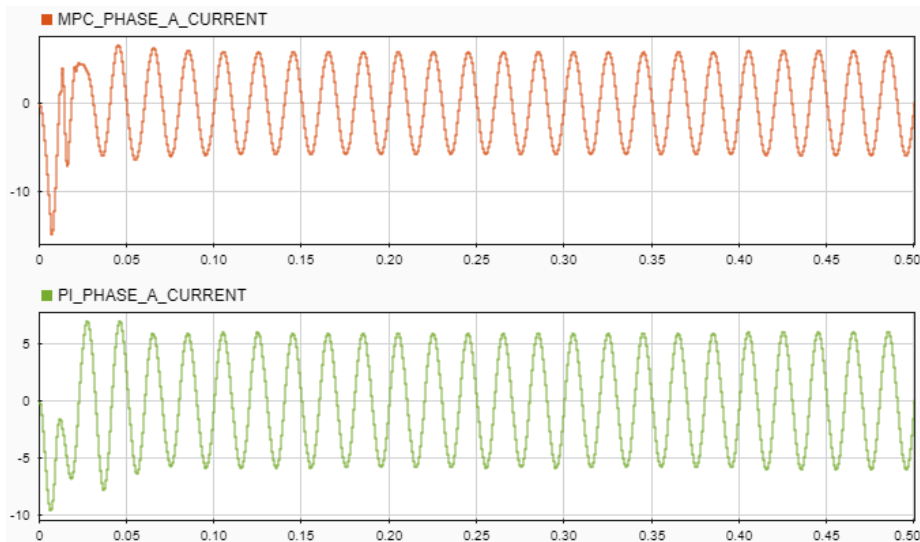

m SLIDING_PHASE_A_CURRENT

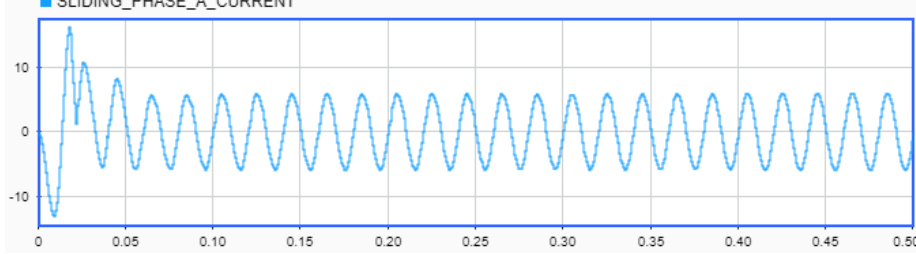

Figure 7. PCC current waveform of phase-a when different controllers are activated for fixed weather condition 

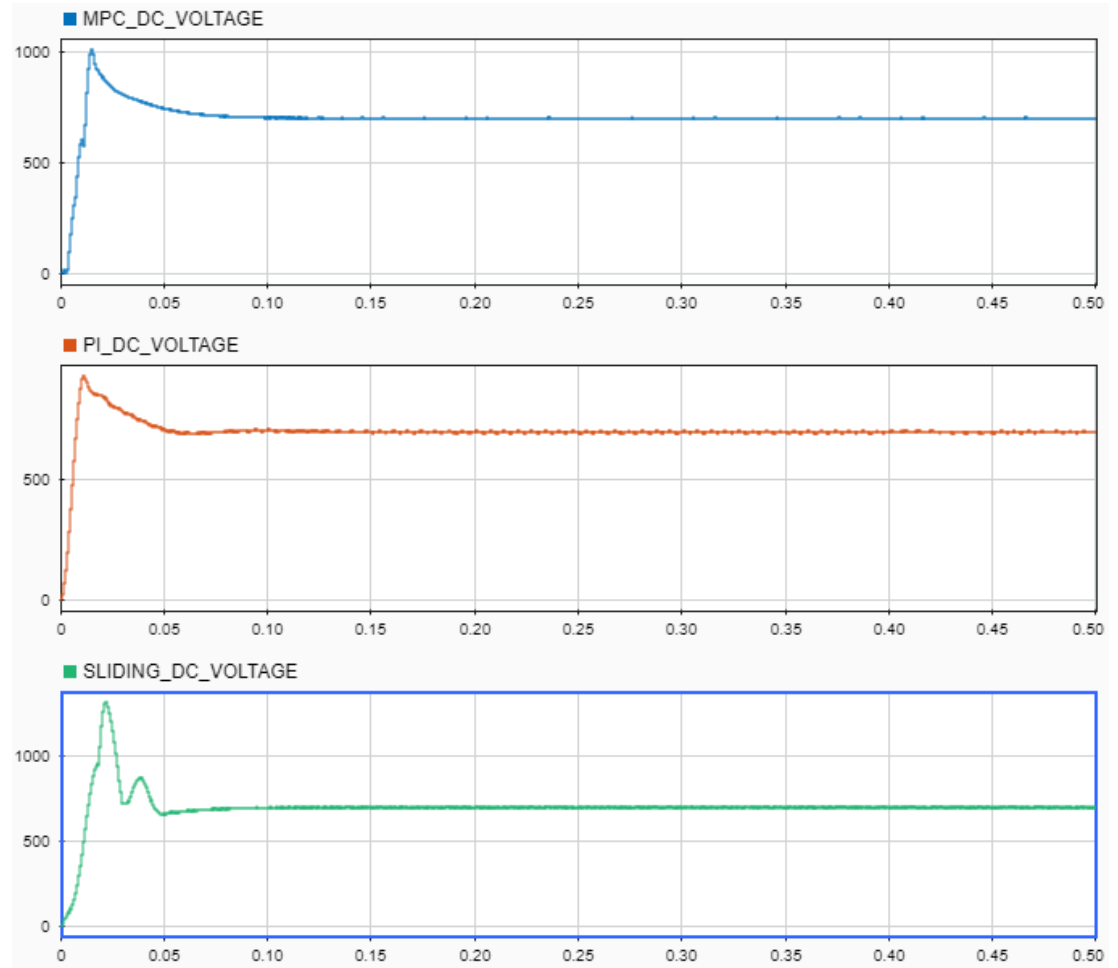

Figure 8. PCC current waveform of phase-a when different controllers are activated for fixed weather condition
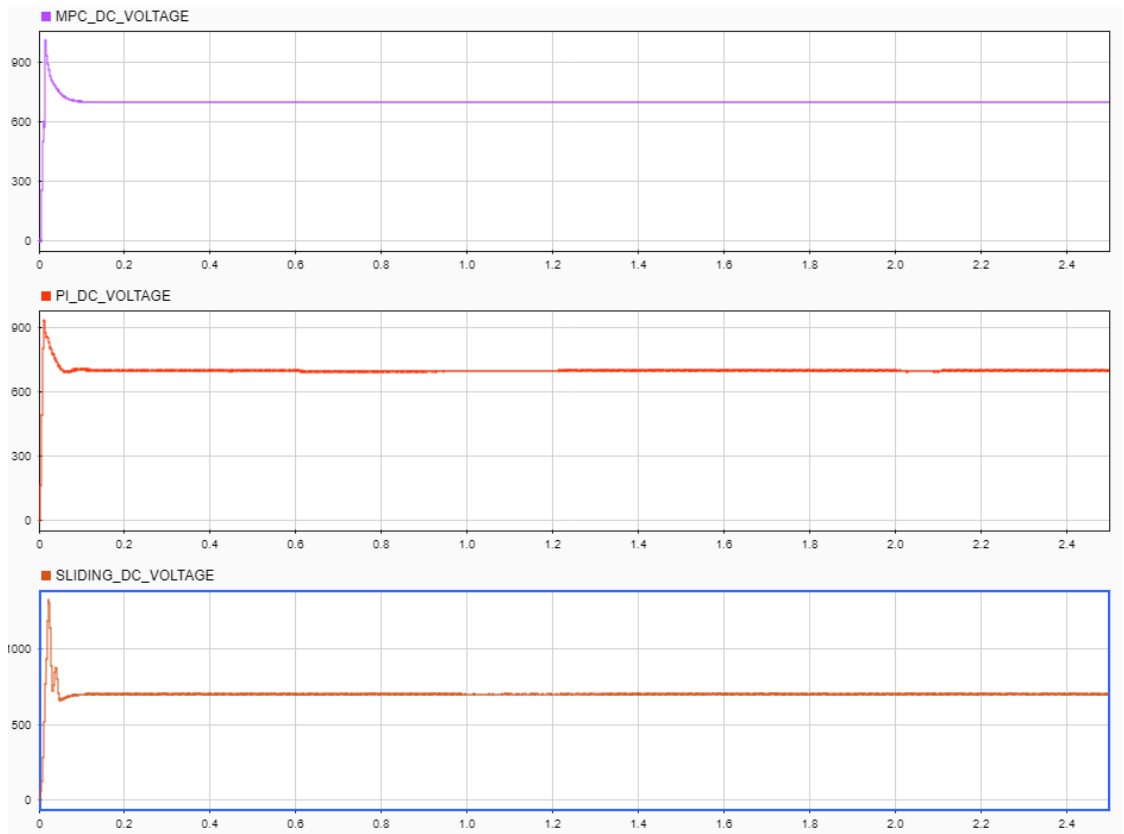

Figure 9. The DC link voltage dynamic responses from the PV system under changing weather conditions 


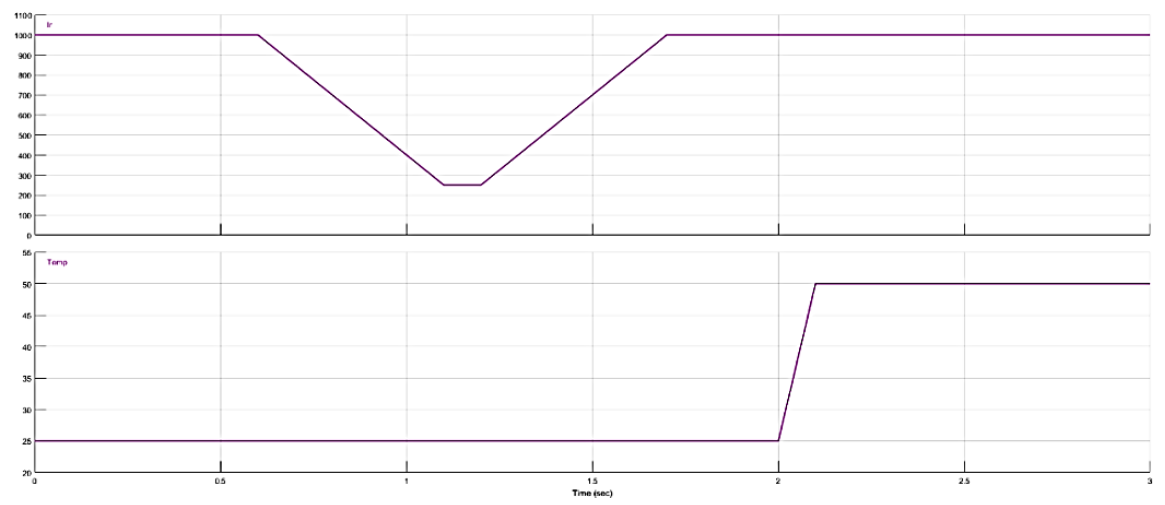

Figure 10. Changing of irradiance and temperature of the PV system
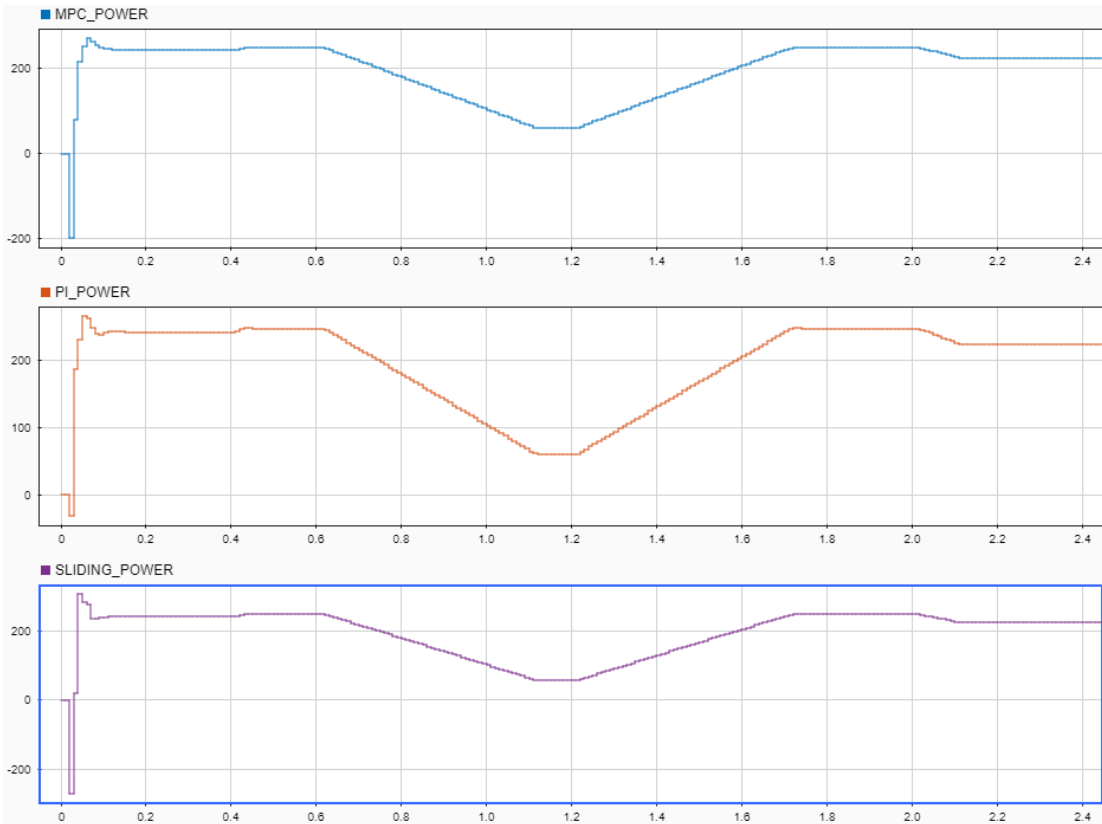

Figure 11. The power output of the PV system under changing weather conditions
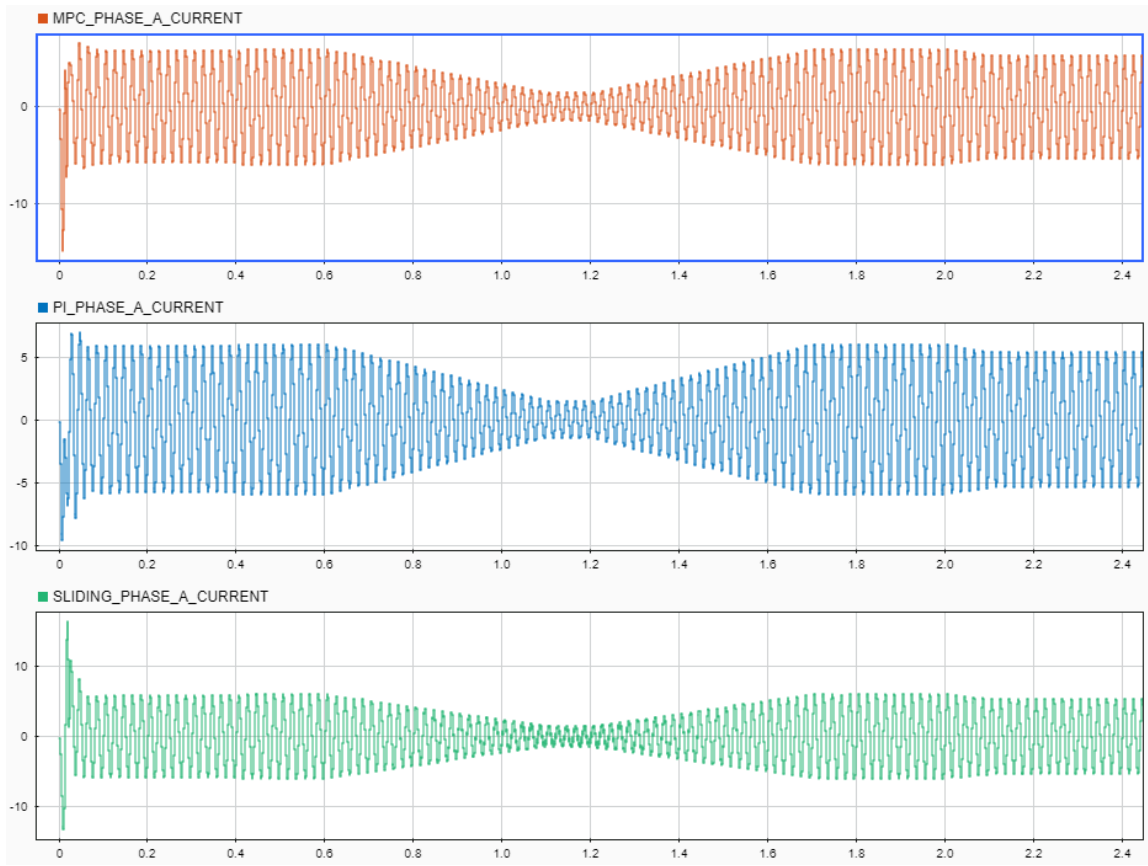

Figure 12. PCC current waveform of phase-a under changing weather conditions 

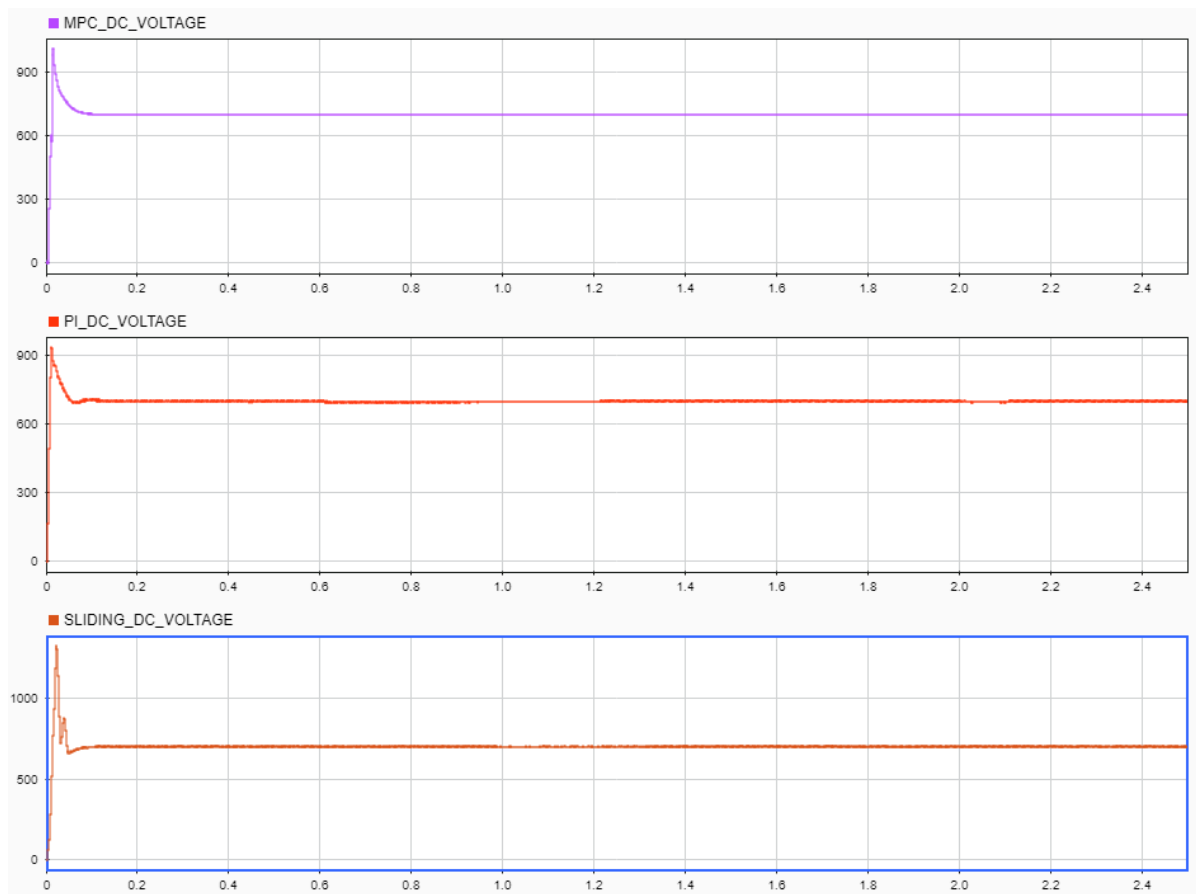

Figure 13. The DC link voltage of the NPC inverter when different controllers are activated under changing weather conditions

\section{CONFLICTS OF INTEREST}

No conflict of interest was declared by the authors.

\section{REFERENCES}

[1] Guo, B., Su, M., Wang, H., "Observer-based second-order sliding mode control for grid-connected VSI with LCL-type filter under weak grid”, Electric Power System Research, 183: 106270, (2020).

[2] Lekouaghet, B., Boukabou, A., Lourci, N., "Control of PV grid connected systems using MPC technique and different inverter configuration models", Electric Power System Research, 154: 287298, (2018).

[3] Lakshmi, M., Hemamalini, S., "Decoupled control of grid connected photovoltaic system using fractional order controller", Ain Shams Engineering Journal, 9(4): 927-937, (2018).

[4] Behera, A.A., Swain, S., Mandavi, D.S., "Comparison of Performance Analysis of Different Control Structures", Department of Electronics \& Communication Engineering National Institute of Technology, Rourkela, (2012).

[5] Rodríguez, J., Cortés, C., "Predictive control of Power Converters and Electrical Drives", A Johan Wiley \& Sons, Ltd., (2012).

[6] Pimentel, S.P., Husev, O., Vinnikov, D., Stepenko, S., Kutt, L., Rodriguez, J., “A Comparison of a Discrete-Time PI and an Indirect MPC Current Controllers for a Single-Phase Grid-Connected Inverter Operating with Distorted Grid and Significant Computation Feedback Delay", 2019 IEEE 15th Brazilian Power Electronics Conference and 5th IEEE Southern Power Electronics Conference, Santos, Brazil, (2020).

[7] Valencia-Paloma, G., Rosister, J.A., "Comparison between an auto-tuned PI controller, a predictive controller and a predictive functional controller in elementary dynamic systems", Automatic Control and Systems Engineering, University of Sheffield, UK, 12: 966-974, (2011). 
[8] Aurobinda, B., Bidyadhar, S., Pravat, R., "Comparative Analysis of Sliding Mode Controller and Hysteresis Controller for Active Power Filtering in a Grid connected PV System", International Journal of Emerging Electric Power Systems, 9(1): 20170044, (2018).

[9] Menega, D., Sankaranarayanan, V., "Performance comparison for grid connected photovoltaic system using sliding mode control", Journal of King Saud University - Engineering Sciences, 33(4): 276-283, (2021).

[10] Al-Refai, A.M., "Design and simulation analysis of $100 \mathrm{MW}$ grid-connected solar photovoltaic power system at Tripoli-Libya", International Journal of Electrical and Electronics Engineering, 9(2): 408, (2017).

[11] Hauke, B., "Basic calculation of a boost converter's power stage. USA: Texas Instruments", Texas Instruments Application Report, (2014).

[12] Schonberger, J., "A single phase multi-string PV inverter with minimal bus capacitance", Proceedings of the 13th European Conference on Power Electronics and Applications, Barcelona, Spain, (2009).

[13] Gao, F., Li, D., Loh, P.C., "Indirect dc-link voltage control of two-stage single-phase PV inverter", Proceedings of the IEEE Energy Conversion Congress and Exposition, San Jose, CA, USA, (2009).

[14] Kasal, G.K., Singh, B., "Voltage and frequency controllers for an asynchronous generator-based isolated wind energy conversion system”, IEEE Transactions on Energy Conversion, 26(2): 402-416, (2011).

[15] Büyük, M., Tan, A., Tümay, M., "Topologies, generalized designs, passive and active damping methods of switching ripple filters for voltage source inverter: A comprehensive review", Renewable and Sustainable Energy Reviews, 62: 46-69, (2016).

[16] Macit, E., "Design and control of three phase grid connected PV system with 1 MW power capacity", Master Thesis, Gaziantep University, Gaziantep, (2020).

[17] Prodanovic, M., Green, T. C., "Control and filter design of three-phase inverters for high power quality grid connection", IEEE Transactions on Power Electronics, 18(1): 373 380, (2003).

[18] Ahmed, K., Finney, S., Williams, B., "Passive Filter Design for Three-Phase Inverter Interfacing in Distributed Generation", Compatibility in Power Electronics, Gdansk, (2007).

[19] Liserre, M., Blaabjerg, F., Hansen, S., "Design and control of an LCL-filter-based three-phase active rectifier”, IEEE Transactions on Industry Applications, 41: 1281-1291, (2005).

[20] Han, Y., Luo, M., Zhao, X., Guerrero, J. M., Xu, L., "Comparative Performance Evaluation of Orthogonal-Signal-Generators-Based Single-Phase PLL Algorithms", IEEE Transactions on Power Electronics, 31: 3932-3944, (2016).

[21] "IEEE Guide for Application and Specification of Harmonic Filters", IEEE Std 1531, 1-60, (2003).

[22] Reznik, A., Simoes, M. G., Al-Durra, A., Muyeen, S. M., "LCL filter design and performance analysis for grid-interconnected systems", IEEE Transactions on Industry Applications, 50(2): 12251232, (2014).

[23] Bauer, J., "Single Phase Voltage Source Inverter Photovoltaic Application", Acta Polytechnica, 50(4): 7-11, (2010). 
[24] Prasad, V. H., "Average current mode control of a voltage source inverter connected to the grid: Application to different filter cells", Master's Thesis, Department of Electrical Engineering, Virginia Tech, Blacksburg, Virginia, (1997).

[25] Araújo, S. V., Engler, A., Luiz, F., Antunes, M., "LCL Filter design for grid-connected NPC inverters in offshore wind turbines", The 7th International Conference on Power Electronics, Liserre EXCO, Daegu, Korea, (2007).

[26] Lettl, J., Bauer, J., Linhart, L., "Comparison of Different Filter Types for Grid Connected Inverter", Progress in Electromagnetics Research Symposium Proceedings, Marrakesh, Morocco, (2011).

[27] Hassaine, L., Olias, E., Quintero, J., "Overview of power inverter topologies and control structures for grid connected photovoltaic systems", Renewable and Sustainable Energy Reviews, 30: 796-807, (2014).

[28] Afghoul, H., Krim, F., "Comparison between pi and fuzzy dpc control of a shunt active power filter", Proceedings of the IEEE International Energy Conference and Exhibition, Florence, Italy, (2012).

[29] Suresh, Y., Panda, A. K., Suresh, M., "Real-time implementation of adaptive fuzzy hysteresis-band current control technique for shunt active power filter", IET Power Electron, 5: 1188-1195, (2012).

[30] Huang, T., Shi, X., Sun, Y., Wang, D., "Three-phase photovoltaic grid-connected inverter based on feed forward decoupling control", 2013 International Conference on Materials for Renewable Energy and Environment, Chengdu, (2013).

[31] IEEE PES. IEEE Std 1459-2010, "IEEE standard definitions for the measurement of electric power quantities under sinusoidal, nonsinusoidal, balanced, or unbalanced conditions", IEEE Power \& Energy Society, New York, (2010).

[32] Akagi, H., Ogasawara, S., Kim, H., "The theory of instantaneous power in three-phase four-wire systems: a comprehensive approach", IEEE Industry Applications Society, 1: 431-439, (1999).

[33] Khalifa, A. S., El-Saadany, E. F., "Control of Three Phase Grid Connected Photovoltaic Power Systems", IEEE, (2010).

[34] Nabae, A., Takahashi, I., Akagi, H., "A New Neutral-Point-Clamped PWM Inverter”, IEEE Transactions on Industry Applications, IA-17(5): 518-523, (1981).

[35] Wiechmann, E., Aqueveque, P., Rodriguez, J., "On the Efficiency of Voltage Source and Current Source Source Inverters for High Power Drives", IEEE Transactions on Industrial Electronics, (2008).

[36] Rodríguez, J., Pontt, J., Silva, C. A., Correa, P., Lezana, P., Cortés, P., Ammann, U., "Predictive Current Control of a Voltage Source Inverter", IEEE Transaction on Industrial Electronics, 54(1): 496-497, (2007). 